\title{
Antecedent of Organizational Citizenship Behavior: Positive and Negative Affectivity
}

\author{
Keumala Hayati ${ }^{1}$, Indra Caniago ${ }^{2}$ \\ \{keumala.hayati@feb.unila.ac.id ${ }^{1}$, igo@darmajaya.ac.id $\left.{ }^{2}\right\}$ \\ Management Department, Faculty of Economics and Business, University of Lampung, Lampung-Indonesia ${ }^{1}$ \\ Accounting Department, Faculty of Economics and Business, IBI Darmajaya, Lampung-Indonesia ${ }^{2}$
}

\begin{abstract}
This set of tests sought to examine the influence of affectivity on OCB. The use of Affective Event Theory could have definitively influenced the results of this study. There have been limited studies on the impact of positive and negative affectivity on OCB simultaneously. Overall, the study of the effect of negative affectivity on OCB is inconclusive. This study identifies the area of Sharia Banks as an area requiring further investigation. The sample is 115 employees from four Sharia banks in Indonesia. The findings show that positive affectivity influence OCB positively. But also, negative affectivity influence OCB negatively. This study suggests that employees who experience positive feelings will behave in sportsmanship, altruism, politeness, awareness, and civic virtue. In contrast, employees with negative feelings tend to impact behavior negatively.
\end{abstract}

Keywords: Organizational Citizenship Behavior, Positive Affectivity, Negative Affectivity, Sharia Banks

\section{Introduction}

Parameters used to describe organizational citizenship behavior (OCB) are individual discretionary behavior not directly recognized by the formal reward system. In the aggregate, it promotes the effectiveness of organizational functions [1]. OCB has been extensively studied [2] for more than two decades. OCB gets considerable attention from scholars because it has a positive impact on organizational success. OCB increased work effectiveness, job satisfaction, organizational commitment, OCB leader behavior, timeliness, helping colleagues, and volunteering, a tendency to reject unwanted behavior such as expressing hatred, cynicism, and nagging at others [3]. A close relationship had demonstrated to disposition, attitudes, emotions, affectivity, and OCB. However, studies of the influence of affectivity on OCB so far are still limited [3].

Affectivity is not an interesting assessment of what is out there. Affectivity at work is what individuals feel at work, related to pleasant feelings [4]. Affectivity divide into two, positive affectivity and negative affectivity. Positive affectivity can influence OCB and work attitude (e.g., [3], [5], [6]).

[6] found that negative affectivity did not influence OCB. However, another study found that negative affectivity influences organizational and interpersonal deviance [7] and service-oriented OCB [8]. The findings of previous research indicate a gap in the study of the influence of negative affectivity on OCB.

Studies of the influence of positive and negative affectivity on OCB have been limited ([6], [8]). This study will further examine the effect of positive and negative affectivity on OCB based on Affective Event Theory (AET). The context of this research is sharia banking. The world of sharia banking is growing fast in Indonesia [9], so it is interesting to study employee behavior within the organization.

This research contributes to two things. First, this study contributes to OCB in both perspectives: positive and negative experience. The study of the effect of negative affectivity on OCB is inconclusive. The novelty of this study is the finding of the effect of negative affectivity on OCB. Second, this study contributes to Affective Event Theory (AET) by using this theory in the constructs relationship. This theory sees the cause and effect of affective experience at work [10]. Third, the contribution of OCB studies to the sharia banking world. As a service organization, the employees feeling about the situation will influence the service [8]. Therefore employee affectivity will affect outcomes, in this case, OCB.

\section{Literature Review}

OCB define extensively in the literature. OCB refers to a series of voluntary employee behaviors that are not officially expected by the company. OCB is characterized by sportsmanship, altruism, politeness, awareness, and civic virtue [11]. The main definitions of OCB are summarized as behaviors that facilitate organizational 
performance [12]. Previous experts connected OCB with job satisfaction [10]. This relationship base on social psychological findings that individuals with positive moods tend to prefer helping others than individuals with negative or neutral moods. A positive mood will produce extra-role behaviors that protect the organization [12].

Dispositional traits influence individual behavior. Each individual has a different dispositional trait. This difference influences the behavior at work and the way individuals interpret the environment based on different perspectives and ways [13]. This study proposes that positive and negative affectivity will influence on OCB.

\section{The Effect of Positive Affectivity on OCB}

Positive affectivity is the individuals' inherent tendency to experience positive and pleasant moods [14]. Positive affectivity is defined as a trait that reflects broad individual differences in positive emotions and selfconcept [15]. Higher levels of positive affectivity tend to increase the level of a positive evaluation of one's experience, trying to change the inner feelings needed so that less involved in surface actions and more in actions from within [16]. High positive affectivity individuals have high self-efficacy, so evaluate uncertain and positively challenging situations and engage in active problem-solving strategies [17].

Positive affectivity predicts to influence OCB based on the Affective Event Theory (AET) [10]. AET explains the role of emotions and evaluative judgments in the relationship between an individual's experience and behavior. This theory's premise is that one's affective response to events at work largely determines subsequent attitudes and behavior. Positive effect on OCB [6], and attitude [5]. Based on this theory, the first hypothesis can develop as below:

H1: Individuals who experience positive affectivity will have a positive effect on OCB

\section{Effect of Negative Affectivity on OCB}

Negative affectivity shows the extent to which a person is sad, detached, or feels pressured by the environment, showing a tendency to experience emotions damaging [18]. Affectivity negative is one's stable tendency to experience negative emotions over time and situational differences [14]. Unlike positive affect, individuals with negative affect tend to be agitated in experiencing ambiguous conditions and often feel dissatisfied and unable to cross time and situations [19]. Negative affectivity of individuals tends to interpret the situation negatively, resulting in negative attitudes. Based on the AET theory, someone who experiences negative affectivity will not have a good effect on his OCB. Thus the following hypothesis can be developed:

H2: Individuals who experience negative affectivity will negatively affect OCB

\section{Research Method}

The sample of this study is employees of sharia banking in Lampung. Five sharia banks participated. One hundred and fifteen questionnaires returned with 61 male employees (53 percent) and 54 female employees (47 percent).

OCB was measured by 20 items developed by [20]. The measurement uses a Likert scale score of 1 to 5 ( 1 for strongly disagree, while 5 for strongly agree). All items are valid, and the alpha coefficient for the scale of OCB in the current study is 0.771 .

Affection is a widespread feeling that includes emotions, moods, and temperaments [21]. Positive affectivity measured by ten items and negative affectivity measured ten items [22]. The measurement uses a Likert scale score of 1 to 5 ( 1 for strongly disagree, while 5 for strongly agree). All items are valid, and the alpha coefficient of positive affectivity is 0.909 , while the negative affectivity is 0.904 .

Variables control in this study are age and gender. Age was measured as a continuous variable, while gender $(1=$ male, $2=$ female $)$ was measured as a categorical variable.

\section{Results and Discussion}

Descriptive statistics, inter-correlations, and measurement reliability showed in Table 1. OCB correlates with positive and negative affectivity. Negative affectivity negatively correlates with OCB. Furthermore, hypothesis testing using regression showed in Table 2. The hypothesis testing results show that $\mathrm{H} 1$ is supported, positive affectivity influence on OCB. H2 test results also supported that negative affectivity influence negatively on OCB.

The results of this study indicate that the positive affectivity experienced by employees today influence on OCB. This result support previous studies [6], and the AET theory explains this situation. Employees who 
experience positive affectivity are more willing to show OCB because they feel good. Employees who feel good feelings prefer to look positively because of the positive affectivity impact on a positive attitude [5]. Someone who feels affective well-being that is feeling happy with his life and work will influence OCB [3]. This result also shows that someone with positive affectivity tends to behave in sportsmanship, altruism, politeness, awareness, and civil virtues [11].

The analysis also shows negative affectivity on OCB. This result is different from [6], who found that negative affectivity had no significant effect on OCB. However, this finding is in line with the findings of [8]. Individuals who experience negative affectivity will negatively influence OCB because there are negative feelings. Negative affectivity individuals tend to interpret the situation negatively, resulting in negative attitudes. So that someone who experiences negative affectivity tends to influence negatively on sportsmanship, altruism, politeness, awareness, and civic virtue [11].

Table 1. Descriptive Statistics, Inter-Correlation, and Reliability

\begin{tabular}{llrrrrrrr}
\hline No & & Mean & SD & 1 & 2 & 3 & 4 & 5 \\
\hline 1 & Age & 1.0348 & .18403 & & & & & \\
2 & Gender & 1.4696 & .50126 & .012 & & & & \\
3 & Negative Affectivity & 2.0835 & .52715 & -.084 & .006 & $(.904)$ & & \\
4 & Positive Affectivity & 4.4417 & .62967 & .131 & .112 & .039 & $(.909)$ & \\
5 & OCB & 3.9492 & .34637 & .005 & -.040 & $-.261^{* *}$ & $.205^{*}$ & $(.771)$ \\
\hline$* *$ Correlation is significant at the 0.01 level (2-tailed). & & & & \\
$*$ *. Correlation is significant at the 0.05 level (2-tailed). & & & &
\end{tabular}

Table 2. Regression Analysis to Predict the Affective State

\begin{tabular}{lrrrr}
\hline & $\beta$ & \multicolumn{1}{c}{$\mathrm{t}$} & \multicolumn{1}{c}{ Sig. } \\
\hline (Constant) & & 12.998 & .000 \\
Gender & -.063 & -.705 & .482 \\
Age & -.047 & -.523 & .602 \\
Positive affectivity & .229 & 2.517 & .013 \\
Negative affectivity & -.273 & -3.043 & .003 \\
\hline
\end{tabular}

Employees who feel positive feelings or moods tend to show OCB intention compared to employees who have negative affectivity. The theoretical justification explains why employees who have positive feelings will exhibit OCB. It could be that employees who feel positive affectivity will manage their good emotions longer. They tend to see more positively the situation of the organization and its co-workers.

Greater attention should be paid to negative affectivity. Employees who feel negative emotions tend to behave negatively towards OCB. Work demands can impact anxiety, while social support can affect depression (e.g., [23], [24]). These negative feelings will have an impact on employees not to show OCB in the workplace.

\section{Conclusions}

This study examines the influence of positive and negative affectivity on OCB. OCB is individual discretionary behavior that is not directly recognized by the formal reward system, and in the aggregate, promotes the effectiveness of organizational functions [1]. OCB studied extensively so far, but antecedents of positive and negative affectivity on OCB are still limited. The test results of this study indicate that positive affectivity has a positive influence on OCB. Conversely, negative affectivity influences negatively on OCB. This finding shows that individuals who experience positive affectivity tend to behave positively like sportsmanship, altruism, politeness, awareness, and civil virtues. However, someone who experiences negative affectivity negatively influences sportsmanship, altruism, politeness, awareness, and civic virtue.

The theoretical implications of this study are as follows. This research has implications that both positive and negative affectivity influence on OCB. This finding confirms that individuals with positive affectivity will positively influence OCB. Nevertheless, individuals with negative affectivity will negatively impact on OCB. Another theoretical implication is that AET can explain the phenomenon of positive and negative affectivity on OCB.

The managerial implication is that organizations need to maintain positive employee feelings. Positive feelings will positively impact employee behavior so that it will have a positive effect on service to customer. On the other hand, organizations that do not deal with negative employee feelings will harm employee behavior. 
Therefore, it is essential to pay attention to the means of maintaining positive feelings. Workload, social support, various conflicts, and other problems, will have an impact on other negative feelings and further impact negatively on OCB.

Aside from the implications, this study has limitations. This research was conducted cross-sectionally so that it only captures the phenomenon at the time of this study. Longitudinal research will be able to capture the phenomenon of the influence of affectivity on OCB in the long run.

\section{Acknowledgment}

I would like to thank the Faculty of Economics and Business, the University of Lampung for funding the publication of this paper.

\section{References}

[1] D. W. Organ, “Organizational citizenship behavior: It's construct clean-up time,” Hum. Perform., vol. 10, p. 85-97, 1997.

[2] D. W. Organ and K. Ryan, "A Meta-Analytic Review of Attitudinal and Dispositional Predictors of Organizational Citizenship Behavior,” Pers. Psychol., vol. 48, pp. 775-802, 1995.

[3] J. Xu, B. Xie, and B. Chung, "Bridging the Gap between Affective Well-Being and Organizational Citizenship Behavior: The Role of Work Engagement and Collectivist Orientation," Int. J. Environ. Res. Public Health, vol. 16, pp. 1-16, 2019.

[4] D. W. Organ and J. P. Near, "Cognition vs. affect in measures of job satisfaction," Int. J. Psychol., vol. 20, pp. 241-253, 1985.

[5] K. Mignonac and O. Herrbach, "Linking Work Events, Affective States, and Attitudes: An Empirical Study of Managers’ Emotions," J. Bus. Psychol., vol. 19, pp. 221-240, 2004.

[6] S. Williams and W. Z. Shiaw, "Mood and Organizational Citizenship Behavior: The Effects of Positive Affect on Employee Organizational Citizenship Behavior Intentions," J. Psychol. Interdiscip. Appl., vol. 133, pp. 656-668, 1999.

[7] K. Aquino, M. U. Lewis, and M. Bradfield, “Justice Constructs, Negative Affectivity, and Employee Deviance: a Proposed Model and Empirical Test,” J. Organ. Behav., vol. 20, pp. 1073-1091, 2009.

[8] A. K. Jain, N. K. Malhotra, and C. Guna, "Positive and Negative Affectivity as Mediators of Volunteerism and Service-Oriented Citizenship Behavior and Customer Loyalty," Psychol. Mark., vol. 29, pp. 1004-1017, 2012.

[9] O. Lisa and B. Hermanto, “Analysis of Risk Profile, Good Corporate Governance, Earnings, and Capital (Rgec) in Syariah Commercial Banks and Conventional Commercial Banks,” Int. J. Soc. Sci. Bus., vol. 4, pp. 58-65, 2020.

[10] H. M. Weiss and R. Cropanzano, "Affective Events Theory: A theoretical discussion of the structure, causes, and consequences of affective experiences at work," B. M. Staw L. L. Cummings (Eds.), Res. Organ. Behav. An Annu. Ser. Anal. essays Crit. Rev., no. 18, pp. 1-74, 1996.

[11] D. W. Organ, "The motivational basis of organizational citizenship behavior," Res. Organ. Behav., vol. 12, pp. 43-72, 1990.

[12] K. Lee and N. J. Allen, “Organizational Citizenship Behavior and Workplace Deviance: The Role of Affect and Cognitions," J. Appl. Psychol., no. 87, pp. 131-142, 2002.

[13] N. A. Bowling, E. A. Hendricks, and S. H. Wagner, "Positive and Negative Affectivity and Facet Satisfaction: A Meta-Analysis.," J. Bus. Psychol., vol. 23, pp. 115-125, 2008.

[14] D. Watson, L. Clark, and A. Tellegen, "Development and Validation of Brief Measures of Positive and Negative Affect: The PANAS Scales,” J. Pers. Soc. Psychol., vol. 54, pp. 1064-1070, 1988.

[15] R. K. Chiu and A. M. Francesco, "Dispositional traits and turnover intention: Examining the mediating role of job satisfaction and affective commitment," Int. J. Manpow., vol. 24, pp. 284-298, 2003.

[16] J. Diefendorff, M. Croyle, and R. Gosserand, "The Dimensionality and Aantecedents of Emotional Labor Strategies,” J. Vocat. Behav., vol. 66, pp. 339-357, 2005.

[17] E. Ünler and B. Kılıç, "Paternalistic Leadership and Employee Organizational Attitudes: The Role of Positive/Negative Affectivity,” SAGE Open, vol. July-Septe, pp. 1-14, 2019.

[18] W. Hochwarter, "Lmx and Job Tension: Linear And Non-Linear Effects and Affectivity," J. Bus. Psychol., vol. 19, no. 4, pp. 505-520, 2005.

[19] R. Cropanzano, K. James, and M. A. Konovsky, "Dispositional Affectivity as A Predictor of Work Attitudes and Job Performance,” J. Organ. Behav., vol. 14, pp. 595-606, 1993. 
[20] S. Fox, P. E. Spector, A. Goh, K. Bruursema, and S. R. Kessler, "The Deviant Citizen: Measuring Potential Positive Relations Between Counterproductive Work Behavior and Organizational Citizenship Behavior," J. Occup. Organ. Psychol., vol. 85, pp. 199-220, 2012.

[21] R. K. Smollan, "Minds, Hearts and Deeds: Cognitive, Affective and Behavioural Responses to Change," J. Chang. Manag., vol. 6, no. 2, p. 2006, 2006.

[22] J. R. Crawford and J. D. Henry, "The Positive and Negative Affect Schedule (PANAS): Construct Validity, Measurement Properties, and Normative Data in a Large Non-Clinical Sample," Br. J. Clin. Psychol., vol. 43, pp. 245-265, 2004.

[23] D. E. Broadbent, “The Clinical Impact of Job Design,” Br. J. Clin. Psychol., vol. 24, pp. 33-44, 1985. [24] H. M. Weiss, K. Suckow, and R. Cropanzano, "Effects of Justice Conditions on Discrete Emotions," J. Appl. Psychol., vol. 84, pp. 786-794, 1999. 